\title{
ENERGETIC INVESTIGATION OF ENERGY RECOVERY TECHNOLOGIES IN AIR HANDLING UNITS
}

\author{
L. F. AL-HYARI ${ }^{\mathrm{a}}, M . K A S S A I^{\mathrm{b}}$ \\ Department of Building Services and Process Engineering, Budapest University of Technology and Economics, Budapest, Hungary \\ a E-mail: laith.alhyari@yahoo.com \\ bE-mail:kas.miklos@gmail.com
}

\begin{abstract}
The statistical data show that the application of active cooling is spread widely in residential and commercial buildings. In these buildings, the ventilation is significantly increased in the whole energy consumption. There are similar problems in the operation of post-insulation of existing buildings. In this case, the energy consumption of the ventilation system gives a major proportion of the whole building services energy consumption. The opportuneness of this research shows that the actual available calculation procedures and technical designing data are only rough approximations for analyzing the energy consumption of air handling units and the energy saved by the integrated heat or energy recovery units. There are not exact methods and unequivocal technical data. In previous researches, the production and development companies have not investigated the effectiveness of the energy recovery units under difference ambient air conditions and the period of defrost cycle when the heat recovery can only partly operate under difference ambient air temperatures. During this term, a re-heater has to fully heat up the ambient cold air to the temperature of supplied air and generate the required heating demand to provide the necessary indoor air temperature.
\end{abstract}

Keywords: energy recovery, energy wheel, AHU, effectiveness

\section{Introduction}

There were several investigations and experimental works executed regarding heat and energy recovery techniques in air handling units (AHU). Plenty of air-handling units these days are equipped with energy recovery units, with target of decrease the energy consumptions in buildings in cooling and heating. The effectiveness of the energy recovery units is used to calculate the energy savings. However, air handling units usually did not work as it planned to be due leakage in air ducts that might decrease significantly the efficiency of heat or energy recovery system. In addition, these units need electrical energy for fans, which may be more precious than saved heat energy. In addition, the utilization of energy recovery technologies decreases the use of non-renewable resources and enhances a purifier environment. Previous work by researchers was highlighted in the open literature in order to identify the progress and development of rotary energy wheels [1-7].

\section{Previous studies}

Mihajlo et al. investigated the sorption property data for different types of molecular sieves (for $3 \AA$, $5 \AA$ and $13 \mathrm{X}$ ) that were presented in equation form.

The connection between proportions of heat of sorption to the latent heat as a function of moisture absorption were determined. They found that heat of sorption could be $50 \%$ greater than the latent heat of vaporization for the different types of molecular sieves considered here. Heat of sorption with equilibrium isotherms data are were consolidated into a numerical model of the nonlinear energy transfer processes that take place in enthalpy wheels [8].

Experimental investigation had been executed by Sparrow et al. in a vast facility, to determine the operating conditions of a regenerative energy wheel. The sensible and moisture transfer effectiveness of a regenerative energy wheel device had been measured in a particular experimental facility. All the experiments were executed at a rotational speed equal to $20 \mathrm{rpm}$.

This is an open-access article distributed under the terms of the Creative Commons Attribution-NonCommercial 4.0 International License (https://creativecommons.org/licenses/by-nc/4.0/), which permits unrestricted use, distribution, and reproduction in any medium for non-commercial purposes, provided the original author and source are credited, a link to the CC License is provided, and changes - if any - are indicated. 
They found that the sensible effectiveness decreases with increasing flowrate and when the flowrates were matchless, higher values of effectiveness were came across. As for the moisture transfer effectiveness the characteristic trend decreasing with increasing flowrate. However, it was noticed that the moisture transfer effectiveness is a bit lower than the sensible effectiveness [9].

Fathieh et al. studied air-to-air rotary energy exchangers that used in ventilation systems to reduce the energy consumption required in industrial and commercial buildings. The effects of silica gel microphysical properties, i.e., pore width $\left(P_{w}\right)$, specific surface area (SA), and particle size $\left(d_{p}\right)$, on the moisture recovery efficiency (latent effectiveness) of energy wheels were investigated. Three silica gel samples with different particle size and pore width $\left(55 \mu \mathrm{m}-77 \mathrm{~A}^{\circ}\right.$, $150 \mu \mathrm{m}-63 \mathrm{~A}^{\circ}$, and $160 \mu \mathrm{m}-115 \mathrm{~A}^{\circ}$ ) were selected to coat small-scale energy exchangers. The results demonstrated that the transient humidity response was mainly specified by the desiccant pore size distribution, specific surface area, and mass of the coating. The transient analytical model was used to calculate the latent effectiveness $\left(E_{L}\right)$ of the exchangers. It was found that the exchanger coated with the smallest pore width $\left(63 \mathrm{~A}^{\circ}\right)$ has the highest available surface area and the highest latent effectiveness $E_{L} \approx 85 \%$ (at wheel speed $0.5 \mathrm{rpm}$ and $R_{e}=43$ ). With almost the same particle size $\left(d_{p}=150 \mu \mathrm{m}\right.$ and $\left.160 \mu \mathrm{m}\right)$, the latent effectiveness increases by $5 \%$ (at wheel speed $20 \mathrm{rpm}$ and $\left.R_{e}=174\right)$ as the pore width reduces from $150 \mathrm{~A}^{\circ}$ to $63 \mathrm{~A}^{\circ}$. Increasing the particle size from $55 \mu \mathrm{m}$ to 150 $\mu \mathrm{m}$ with almost the identical pore width $\left(P_{w}=63 \mathrm{~A}^{\circ}\right.$ and $77 \mathrm{~A}^{\circ}$ ) results in a slight enhancement in the latent effectiveness [10].

Wallin and Claesson improved the energy efficiency of a building with rotating heat recovery system investigated by TrnSys simulation. The evaporator unit was connected to a heat exchanger that was setted in the exhaust airstream after the energy recovery wheel, and the condenser of the heat pump was set to be so that the temperature of return water is increased from the heating coil. The results in their work indicated that it is feasible to adjust a heat pump heat recovery system to an air-handling unit as proposed. For the suggested system, the simulation indicated that the heat recovery can be increased up to $24 \%$, that will give the recovery system energy covering of $97 \%$. The investigations also submitted that the the heat pump efficiency is a significant factor to the overall system efficiency. The Coefficient of Performance of the heat pump was set to be three during the investigation that was calculated by dividing the heat supplied by the heat pump to the electrical energy supplied by the compressor of air-handling system [11].
Rouleta et al. discussed a theoretical point of view for the real energy recovery with air handling units and presented the measurements results of a 13 units. In the top three cases, the real, global heat recovery effectiveness (recovered heat flow rate $(\mathrm{kW})$ / building ventilation heat loss without heat recovery $(\mathrm{kW})$ ) was between $60-70 \%$ for heat recovery units having a nominal effectiveness $E_{\mathrm{HR}}=80 \%$ of the heat recovery unit. In the worst three cases, the global effectiveness was less than $10 \%$. So the heat recovery in these cases saves less energy than it uses. However, the ventilation systems did not affect other qualities like the fresh air have lower concentrations of contaminants [12].

Abe et al. presents an analytical model to predict the effectiveness of rotating energy wheels using the characteristics measured used in non-rotating wheels with a step change in humidity and temperature. A relationship developed between the step change and the rotating response of a rotating energy wheel that assumes the energy wheel conduct as a first order linear system for sensible energy exchange and water vapour. an uncertainty calculations and effectiveness correlations were developed for sensible and latent effectiveness of the rotating energy wheels using the data conducted from the transient measurements. The analytical model showed that as the time constant and wheel speed increase (1) the effectiveness increases and (2) the uncertainty in the effectiveness decreases. Using this model, the effectiveness of rotating energy wheels can predict values with uncertainties between $\pm 3 \%$ to $\pm 5 \%$ [13].

Experimental investigations on desiccant wheel material was performed by Angrisani et al. The desiccant wheel material was reformed through low temperature thermal energy from a micro-cogenerator. The manufacturer provided data and the results obtained by the authors was used to calculate some of the performance parameters. The performance parameters had been estimated as a function of the regenerated temperature, the inlet humidity ratio and the ratio between the regeneration and process air-flow rates, in both cases of regeneration temperature and regeneration thermal power. The obtained results indicated that the dehumidification process has a higher influences is because of the regeneration temperature instead of the regeneration air flow rate. The difference between the data was lower than $17 \%$. Moreover, the maximum difference was less than about $20 \%$. Low values of the root mean square error have been also accomplished. Consequently, the good agreement between manufacturer's data and experimental results should be considered [14].

The performance of desiccant wheels used in air dehumidification has been studied by Zhang and Niu and it was compared with enthalpy recovery wheels. 
A two-dimensional (heat and mass transfer model) was presented taking into considerations the heat conduction, the gaseous diffusion and surface diffusion in axial and the thickness directions. Impacts of the rotary speed on the wheel performance were investigated and compared in the two cases. It was found that the optimum rotary speed for enthalpy recovery is much higher than that for air dehumidification [15].

Simonson and Besant developed a numerical sample for heat and moisture transfer, with frosting and moisture condensation in rotating energy wheels and calculated with experimental data. The sample model was used to study the behavior of the condensation and frosting in rotating wheel and it shows that it was influenced by increasing with humidity, and water-frost will accumulate continuously in the wheel. The performance of energy wheel was also presented for a desiccant coating with a sorption isotherm (molecular sieve) and a linear sorption isotherm (silica gel). The simulation results demonstrate that desiccant with a linear sorption curve is appropriate for energy recovery due to small amounts of condensation frosting for extreme operating conditions. The numerical algorithm is changed from sorption to saturation when the air relative humidity exceeds $100 \%$ and when the wheel speed reduced the uncontrolled condensation and frosting will be reduced. [16].

Nasr et al. review the frosting and defrosting techniques, specifically in air-to-air heat/energy exchangers. The following conclusion on frosting in air-to-air heat/energy exchanger can be made:

- Blockage of the air channels by frost decreases the exchanger's effectiveness considerably. Providing an equal frost deposition pattern would delay blockage.

- Moisture transfer in energy exchangers decreases the frosting limit.

- The available results for energy exchangers are mostly presented for energy wheels.

- Energy wheels with hydroscopic surfaces have lower frosting limit compare to non-hydroscopic wheels.

- Pressure drop monitoring is the most reliable technique of the different method available to detect frost (temperature and effectiveness monitoring, pressure drop measurement, visual inspection) if no visual technique is possible.

- One advantage of hydrophobic surfaces over the hydrophilic surfaces was its stability to retain frost free properties after repeated testing.

- Experiments have shown that hydrophobic can retard the frosting process although, the frosting limit did not change.

- Portion of the recovered energy would be sacrificed or the capital cost would be increased, which makes the techniques impractical in certain cold conditions [17].

Bareschino et al. developed a one-dimensional heat and mass transfer model for desiccant wheel, considering the transient properties of humidity with temperature which called the Variable Properties Model (VPM). The model has been proved using theoretical and experimental data in terms of temperature and humid air profiles at the exhaust of the wheel. Compared to the regular models, significant improvements between numerical predictions and the obtained experimental data have been spotted. it can be summarized that (VPM) calculated data were always be lower than those between the same obtained experimental results and calculated results according to Constant Properties Model (CPM) which consider moist air properties constant with temperature [18].

A numerical model of a recovery wheel used by Goldsworthy et al. to investigate the influence of the equilibrium adsorption on the overall performance of the wheel. The heat and moisture rate, specific heat and density were changed to provide more vision into the limit of heat and mass transfer for low temperature regeneration. Beside, an analysis of the desiccant adsorption shape was carried out for a range of process conditions. The results showed that at temperature lower than $80^{\circ} \mathrm{C}$ regeneration, the supply air exhaust condition from a silica gel enthalpy wheel is restricted by the regeneration relative humidity commercial data for the silica gel was close to achieving the goal with a latent effectiveness close to $85 \%$. A two-dimensional model in heat and mass transfer showed that the maximum efficiency for enthalpy wheel can be obtained when carryover of heat would be least to the supply air stream. At high air velocities, the moisture transfer becomes significant through the wheel material [19].

Jeong and Mumma develop practical effectiveness correlations for desiccant wheel. Linear equations were constructed to calculate the desiccant wheel total effectiveness at nominal operating wheel speeds. The silica gel and molecular sieve wheel were investigated depending on six factors; outside air and temperature of exhaust air, relative humidity, air velocity, and air flow rate. It was found that the air velocity and air flow rate contribute highly to sensible and latent effectiveness. The entering outside air and exhaust air showed a small contributions to sensible effectiveness, and higher contribution to latent effectiveness. The desiccant wheel effectiveness values predicted showed a good agreement with the manufacturer's data and to other desiccant wheel model results [20].

Chung et al. optimized the design parameters of plastic rotary wheels. A numerical model was built and established to predict the performance of a plastic regeneration wheel taking into account the leakage and 
adsorption impacts. The effects of the rotational speed, and purge section angle and aspect ratio on the sensible and latent effectiveness were investigated using the numerical model. The optimum values for wheel speed, purge section angle and aspect ratio in the plastic regeneration wheel were specified. The maximized sensible effectiveness was 0.85 and the minimized moisture or latent effectiveness with using the optimal values was 0.042 , which yielded to an almost $40 \%$ improvement in the moisture effectiveness comparing to the use of the basic design parameters [21].

Neti and Wolfe measured the performance of a silica gel enthalpy wheel. The velocities of process air velocities range from 0.5 to $2.5 \mathrm{~m} / \mathrm{s}$, and the supply temperature range was between 20 to $30{ }^{\circ} \mathrm{C}$ with $100 \%$ relative humidities. The enthalpy data were compared to Maclaine-Cross and Bank's theory and Lambertson's theory. It was found that:

1) The wheel rotational speed for a enthalpy wheel was slow enough to indicate the effectiveness was ruled by the wheel capacity and less by sensible and latent late.

2) Maclaine-Cross and Bank's theory seems to be useful for small scale conditions. The theories seem to be unsuitable for rotational speeds greater than 0.5 and values between $2 \mathrm{rpm}$ and $4 \mathrm{rpm}$.

3) Lambertson's theory predicts the tendency of the experimental data, but the error values were high comparing the measured effectiveness values [22].

Calay and Wanga presented a high performance rotary wheel in cooling, heating and ventilation system depending on reverse cycle heat pump. In the proposed system, the lost energy from the exhaust air was used to preheat/precool the outdoor air before it is supplied inside the building. The combined system provides heating and cooling without extra need from external heating or cooling devices as used in traditional systems. The performance of the proposed hybrid system was better than a conventional system in providing the nominal indoor air quality levels. An average energy saving up to $70 \%$ of heat energy was obtained by using the hybrid system for ventilation applications [23].

De Antonellis et al. tested two different desiccant wheels, calcium carbonate and silica gel based wheel. Sensible and latent effectiveness were estimated under different operating conditions, practically with different inlet temperature, humidity and wheel rotation speed with measuring under balanced and unbalanced air flowrates practical correlations for sensible and latent effectiveness were obtained. The obtained correlations predict compatible values for actual enthalpy wheels effectiveness. The two wheels show similar sensible effectiveness and difference in total pressure, but the silica gel wheel appears to be more efficient in latent heat recovery. Furthermore, the obtained correlations could be a good reference when using in energy programs to predict the total effectiveness and pressure drop of desiccant wheels used for heat and moisture recovery in buildings [24].

Nóbregaa and Brumb discussed the definitions for effectiveness of enthalpy wheels, as well as the physical properties for enthalpy recovery in active and passive dehumidification processes. It was concluded in passive dehumidification that sensible and moisture transfers have inconsistent influences on the enthalpy wheel, making it effectiveness inattentive to the outside conditions. According to that, an increase in the air temperature will signify a greater contribution to the sensible effectiveness to the total effectiveness, and lesser contribution of the latent effectiveness. As for the active dehumidification, it was realized that sensible and latent energy has dual effects, as the capacity increase with increasing regeneration temperature. The results indicated that silica-gel wheel thorough air dehumidification is effective even for a low stimulation temperature [25].

Smith and Svendsen built and simulated equations for room ventilation with moisture absorbance energy wheel. The study assumed that all moisture condensed in the exhaust air stream evaporated into the supply. Simulations evaluated the prospect for moisture and compared the results with sensible recovery ventilation systems. The study also focused on the influenced parameters, such as, relative humidity, and indoor temperature. The rotary heat wheel was appropriate just for single-room ventilation of dry rooms. However, it minimized the relative humidity in each room which is good for health breathing [26].

Ruan et al. developed a one-dimensional mathematical model for heat and mass transfer to calculate the effectiveness of energy recovery wheels in two cases; with purge air and without. The obtained equations and the variables were estimated using a trial and error method. The results of an energy recovery wheel with purge air were presented to find the optimum wheel speed and wheel depth to purse the maximum efficiency for energy wheel with purge air. As for energy recovery wheel without purge air it was validated from pervious results. The distribution of the air temperature and the humidity ratio in energy recovery wheel indicated that the factors have a positive influence on the effectiveness of the wheel. Nevertheless, increasing the depth of the wheel and the rotational wheel speed needs more purge air to block the carryover of polluted air to the supply air, which will affects on the wheel performance [27].

Experimental tests on a silica gel enthalpy wheel done by Angrisani et al. in order to determine the ef- 
fect of wheel speed on its performance. The wheel material was regenerated to a temperature up to $65^{\circ} \mathrm{C}$. The obtained results used to calculate operation parameters for the energy wheel, such that, the latent coefficient of performance, latent effectiveness and the sensible energy ratio (SER). Finally, the impact of inlet air temperature and humidity and the ratio between the process air flow and regenerated air flow at the optimum wheel speed were evaluated. It was found that, for the studied enthalpy wheel, the optimal wheel speed to maximize latent effectiveness depends on the operating parameters will increase when the humidity ratio and regeneration temperature increased. While it reduces when inlet process temperature rises from. The maximum latent effectiveness obtained was up to $60 \%$. And it was obtained with low relative humidity and temperature, and high flow rate and regeneration temperature [28].

Angrisani et al. presented an analytical experiments on the performances of a silica-gel enthalpy wheel. The enthalpy wheel was regenerated by microcogenerator with low temperature thermal energy. The effects of the ambient conditions (outdoor air, relative humidity and regeneration temperature) on the enthalpy wheel performances have been studied; and the enthalpy wheel effectiveness values had been obtained. The obtained results provided helpful information on the studied desiccant wheel. The performance curves make it possible to compare real performances to the ideal conditions [29].

Fathieh et al. aimed in their study to determine the latent effectiveness of a rotary enthalpy wheel through small scale tests. A coating of porous silica gel wheel with particle size $d_{p}=55 \mu \mathrm{m}$, pore width $P_{w}=77.5 \AA$ was settled on an aluminum substrate. The physical properties of wheel were identified and its sorption properties were studied using nitrogen gas adsorption at an adequate temperature. Aside from, the equilibrium condition and moisture sorption on the silica gel particles were studied at $23{ }^{\circ} \mathrm{C}$. The data obtained from dehumidification process was used to determine the effectiveness of a silica gel wheel. Moreover, a correlation equation from the previous literature was used to calculate the latent effectiveness for the wheel and then a comparison between the latent effectiveness were made and it showed close values at $\omega>4 \mathrm{rpm}[30]$.

Ali et al. presented an analytical model depending on predictions of an enthalpy wheel performance implementing measurements obtained from an existing system. The model was built on combinations of equation to calculate the optimal performance depending on input variables related to the material of the enthalpy wheel and the physical properties. The model analyzed the impact of different operating conditions on the enthalpy wheel performance: wheel rotational speed, inlet temperature, relative humidity and velocity of the air. The model was able to estimate the optimal values for wheel speed and pressure difference of the wheel. Moreover, the model appears to be applicable in dehumidification and enthalpy modes and showed a good agreement with the published data, while the resulting Maximum and minimum mean percentage error between the obtained and measured data was $4.6 \%$ and $0.2 \%$, respectively [31].

The performance of solid desiccant wheel was studied by Goodarzia et al. air humidity ratio, mass flow rates, wheel rotational speed and air process temperatures, were the factors investigated in this study. Simulation program was used to calculate output conditions. The performance of a rotary desiccant wheel was investigated based on effectiveness parameters that includes moisture removal capacity, sensible and latent coefficient of performance and afterwards calculating the total coefficient of performance (CoP). In conclusion, all the factors influenced on the $\mathrm{CoP}$ and the MRCs with a positive relation expect inlet temperature [32].

Yamaguchi and Saito focused their studies on a rotary enthalpy wheel. They built a mathematical model and compare it with their experimental results. The model was conducted under several operating conditions and it includes the supply entrance effect in air duct. Effects of the regeneration temperature, wheel thickness, wheel rotational speed and air velocity on the enthalpy wheel performance were studied. In addition, the distribution of temperature and humidity at the exhaust of the enthalpy wheel were measured. It was found, from the pressure drop estimation, that it can be predicted more precisely by considering the inlet region effect. The relative error for measured humidity ratio difference and temperature difference distribution was $3.3 \%$ and $10.8 \%$, respectively. Moreover, the effect of the inlet temperature, the air velocity, wheel rotational speed and wheel thickness on the enthalpy wheel performance were clear and the predicted results had very close values to the measured results [33].

El-Maghlany et al. addressed a modification to improve the energy performance of air conditioning (AC) systems in large buildings that consumes a lot of energy. Intensive treatments units in hospitals was the most energy consumption because the fresh air needed for utilization. In their research the study existing hospital building, focusing on air conditioning system that use fresh air for the intensive treatment unit. In the suggested study, two energy wheels were studied to be equipped to an existing system through exit energy recovery using a Simulation program. The obtained results showed a noticeable reduction in the cooling capacity and therefore, a saving in power consumption around $87 \%$ in winter and 
a low saving in summer with around $13.5 \%$ savings [34].

Dehabadi et al. investigated the performance of starch enthalpy wheel. A high amylose starch coated exchanger was developed, and the inlet humidity was studied at variable conditions of airflow rate and temperature. Dehumidification, regeneration power and the humidity response, and the Moisture Removal Rate were measured. It was found that as the regeneration flow rate and temperature increased it could promote the regeneration power. Despite increasing in the regeneration power, the latent effectiveness decreased when the airflow rate or temperature increased. When flow rate increases from 10 to $50 \mathrm{~L} / \mathrm{min}$ at wheel speed $=2 \mathrm{rpm}$ the effectiveness decreased by $15 \%$. While, the difference in effectiveness is less than $4 \%$ at wheel speed $=20 \mathrm{rpm}$. And as the temperature increased by $15{ }^{\circ} \mathrm{C}$, trivial changes in effectiveness were encountered with difference below $4 \%$ [35].

\section{Overview of this research}

In previous researches as studied in literature review have not investigated the effectiveness of air-to-air energy recovery wheel coated with $3 \AA$ molecular sorption sieve under extreme difference ambient air conditions and different wheel rotation speed as a significant operation parameter by detailed experimental tests.

In this work temperature and humidity based experimental testing will be conducted to get the effec- tiveness values of air-to-air energy recovery wheel coated with $3 \AA$ molecular sorption sieve under steady-state conditions. The optimal wheel rotation speed, resulted an energy efficiency operation by the maximum effectiveness values, will be searched under extreme difference ambient air conditions parameters considering also the possibly forming frost in the energy exchanger. Effectiveness values obtained from experimental tests will be implemented to calculate the energy recovered by the investigated energy wheel under different climate regions using simulation software to get more exact results closer to the real operation.

The scientific results will conclude the effect of wheel rotation speeds (as a significant operating parameter) to the effectiveness of an air handling unit effectiveness of the energy recovery ventilation unit under difference ambient air conditions and will show the optimal operating parameters in the point of view of energy saving. These results can be applicable relatively fast in the practice, and there will be a high interest for these new scientific results also in the building service engineers and experts who works in the practice.

The investigated energy wheel that will be used in this research is a high performance desiccant coatings of the sorption rotor (Molecular Sieve $3 \AA$ ) provide a maximum humidity transfer capacity that substantially reduces the energy demand of the HVAC system based on the product catalogue by a high quality producer (ENVENTUS).

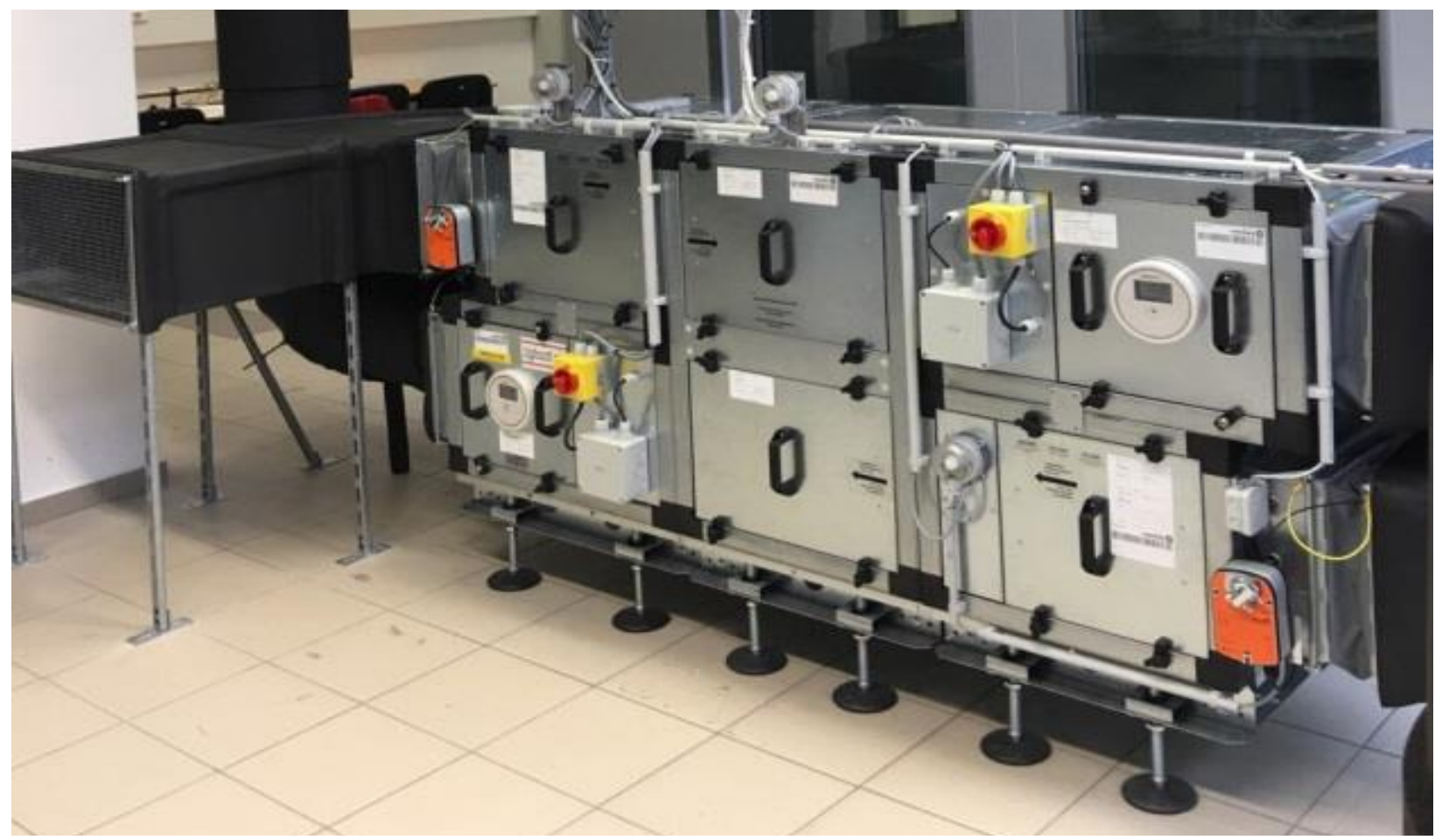

Fig. 1. The experimental test facility 


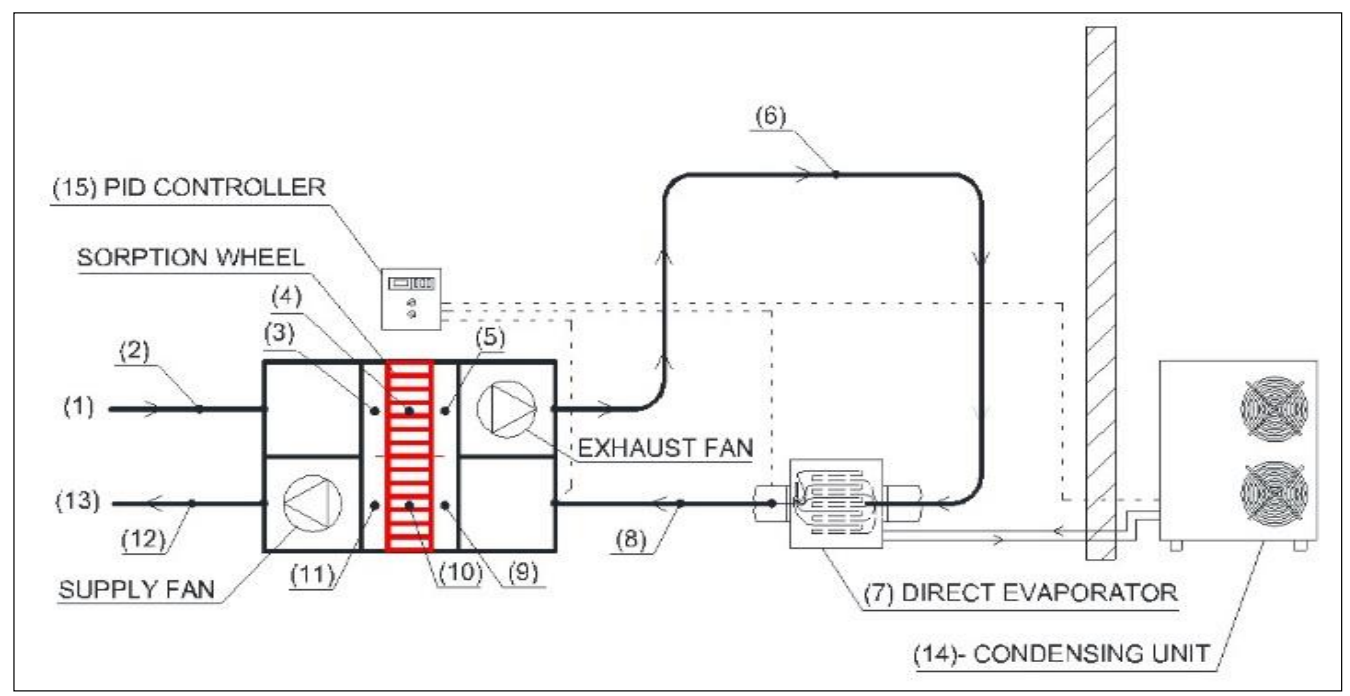

Fig. 2. Summary of rework costs from different authors

\section{Description of the test facility}

The measurement stand (Fig. 1) was set up in the Indoor Air Quality and Thermal Comfort Laboratory of the Budapest University of Technology and Economics. In the course of designing the measurement stand, the primary objective was to develop a measurement device, which is capable of establishing and permanently maintaining extreme outdoor states of air.

Cooling or heating of supply air, as also shown in Fig. 2 was provided by the direct evaporation type plate heat exchanger (marked by (7)), as an ambient air temperature generator, supplied with a coolant of appropriate temperature by the heat pump (15). Supply air (13) was produced from exhaust air (1), thus in the mentioned heat exchanger (7) air already precooled or pre-heated by the heat exchanger had to be cooled/heated further. Thus, more extreme supply input (as ambient) air states could be established with the available cooling/heating capacity.

Table 1 represents the path of air using the marks according to Fig. 2 with the variables measured at each point, and the changes possible in the state of air in the given section.

Table 1. The variables measured at each point in the experimental test facility

\begin{tabular}{|c|c|c|c|c|}
\hline \multicolumn{2}{|c|}{ Path of the air } & \multirow{3}{*}{$\begin{array}{l}\text { Variables } \\
\text { measured }\end{array}$} & \multicolumn{2}{|c|}{ Possible air state change } \\
\hline & & & Heating period & Cooling period \\
\hline (1) & Indoor air (laboratory) & & & \\
\hline (2) & Indoor air duct & & heating, humidifying & heating, humidifying \\
\hline (3) & Sorption wheel (exhaust input) & $\begin{array}{l}t_{\mathrm{ei}}\left[{ }^{\circ} \mathrm{C}\right] \\
\varphi_{\mathrm{ei}}[\%]\end{array}$ & & \\
\hline (4) & Sorption wheel (exhaust side) & & heating + dehumidifying & cooling + dehumidifying \\
\hline (5) & Sorption wheel (exhaust output) & $\begin{array}{l}t_{\mathrm{eo}}\left[{ }^{\circ} \mathrm{C}\right] \\
\varphi_{\mathrm{eo}}[\%]\end{array}$ & & \\
\hline (6) & Exhaust air duct & & humidifying & humidifying \\
\hline (7) & Direct evaporator & & cooling & heating \\
\hline (8) & Fresh air duct & & humidifying & humidifying \\
\hline (9) & Sorption wheel (supply input) & $\begin{array}{l}t_{\mathrm{si}}\left[{ }^{\circ} \mathrm{C}\right] \\
\varphi_{\mathrm{si}}[\%]\end{array}$ & & \\
\hline$(10)$ & Sorption wheel (fresh air side) & & cooling + humidifying & heating + humidifying \\
\hline (11) & Sorption wheel (supply output) & $\begin{array}{l}t_{\mathrm{so}}\left[{ }^{\circ} \mathrm{C}\right] \\
\varphi_{\mathrm{so}}[\%]\end{array}$ & & \\
\hline (12) & Supply air duct & $V_{\mathrm{so}}\left[\mathrm{m}^{3} / \mathrm{h}\right]$ & & \\
\hline (13) & Supply air & & & \\
\hline
\end{tabular}




\section{Acknowledgements}

This research was financially supported by the National Research, Development and Innovation Office of Hungary (grant number NKFIH PD 115614), Budapest, Hungary.

\section{References}

[1] Poos T., Szabo V., Varju E., Sebesi V. (2016), Determination of drying rate at herbs drying with ambient air, Proceedings of the 4th International Scientific Conference on Advances in Mechanical Engineering (ISCAME 2016). Debrecen, Hungary, pp. 408-413.

[2] Kalmár F. (2016), Interrelation between glazing and summer operative temperature in buildings. International Review of Applied Sciences and Engineering, 1, 51-60.

[3] Kalmár T., Kalmár F. (2010), Comfort and energy analysis of heating up. International Review of Applied Sciences and Engineering, 1-2, 35-43.

[4] Nyers J. (2016), A new analytical method for defining the pump's power optimum of a water-to-water heat pump heating system using COP. Thermal Science, DOI: 10.2298/TSCI161110324N.

[5] Nyers J., Kajtar L., Slavica T., Nyers, A. (2014), Investment-savings method for energy-economic optimization of external wall thermal insulation thickness. Energy and Buildings, 86, 268-274.

[6] Nyers J., Garbai L., Nyers A. (2015), A modified mathematical model of heat pump's condenser for analytical optimization. Energy, 80, 706-714.

[7] Sánta R., Lászó G., Igor F. (2017), Numerical investigation of the heat pump system. Journal of Thermal Analysis and Calorimetry, 130(2), 1133-1144.

[8] Golubovic M., Hettiarachchi H., Worek W. (2006), Sorption properties for different types of molecular sieve and their influence on optimum dehumidification performance of desiccant wheels. International Journal of Heat and Mass Transfer, 49, 2802-2809.

[9] Sparrow E., Tong J., Johnson M., Martin G. (2007), Heat and mass transfer characteristics of a rotating regenerative total energy wheel. International Journal of Heat and Mass Transfer, 50, 1631-1636.

[10] Fathieh F., Nezakat M., Evitts R., Simonson C. (2017), Effects of physical and sorption properties of desiccant coating on performance of energy wheels. Journal of Heat Transfer-Transactions of the ASME Volume, 139/0626011.

[11] Wallin J., Claesson J. (2014), Improving heat recovery using retrofitted heat pump in air handling unit with energy wheel. Applied Thermal Engineering, 62, 823e829.

[12] Rouleta C., Heidtb F., Foradinic F., Pibiria M. (2001), Real heat recovery with air handling units. Energy and Buildings, 33, 495-502.

[13] Abe O., Simonson C., Besant R., Shang W. (2006), Effectiveness of energy wheels from transient measurements. Part I: Prediction of effectiveness and uncertainty. International Journal of Heat and Mass Transfer, 49, 52-62.

[14] Angrisani G., Minichiello F., Roselli C., Sasso M. (2012), Experimental analysis on the dehumidification and ther- mal performance of a desiccant wheel. Applied Energy, 92, 563-572.

[15] Zhang L., Niu J. (2002), Performance comparisons of desiccant wheels for air dehumidification and enthalpy recovery. Applied Thermal Engineering, 22, 1347-1367.

[16] Simonson C., Besant R. (1997), Heat and moisture transfer in energy wheels during sorption, condensation, and frosting conditions. Journal of Heat Transfer-Transactions of the ASME Volume, 120/699.

[17] Nasr M., Fauchoux M., Besant R., Simonson C. (2014), A review of frosting in air-to-air energy exchangers. Renewable and Sustainable Energy Reviews, 30, 538-554.

[18] Bareschino P., Diglio G., Pepe F., Angrisani G., Roselli C., Sasso M. (2015), Modelling of a rotary desiccant wheel: Numerical validation of a variable properties model. Applied Thermal Engineering, 78, 640e648.

[19] Goldsworthy M., White S. (2012), Limiting performance mechanisms in desiccant wheel dehumidification. Applied Thermal Engineering, 44, 21e28.

[20] Jeong J., Mumma S. (2005), Practical thermal performance correlations for molecular sieve and silica gel loaded enthalpy wheels. Applied Thermal Engineering, 25, 719-740.

[21] Chung H., Lee J., Kang C., Yongchan K. (2016), Numerical analysis of the performance characteristics and optimal design of a plastic rotary regenerator considering leakage and adsorption. Applied Thermal Engineering, 109, 227237.

[22] Neti S., Wolfe E. I. (2000), Measurements of effectiveness in a silica gel rotary exchanger. Applied Thermal Engineering, 20, 309-322.

[23] Calay R., Wanga W. (2013), A hybrid energy efficient building ventilation system. Applied Thermal Engineering, $57,7 \mathrm{e} 13$.

[24] De Antonellis S., Intini M., Joppolo C., Pedranzini F. (2014), Experimental analysis and practical effectiveness correlations of enthalpy wheels. Energy and Buildings, 84, 316-323.

[25] Nóbregaa C. E. L., Brumb N. C. L. (2012), An analysis of the heat and mass transfer roles in air dehumidification by solid desiccants. Energy and Buildings, 50, 251-258.

[26] Smith K., Svendsen S. (2016), The effect of a rotary heat exchanger in room-based ventilation on indoor humidity in existing apartments in temperate climates. Energy and Buildings, 116, 349-361.

[27] Ruan W., Qu M., Horton T. (2012), Modeling analysis of an enthalpy recovery wheel with purge air. International Journal of Heat and Mass Transfer, 55, 4665-4672.

[28] Angrisani G., Roselli C., Sasso M. (2013), Effect of rotational speed on the performances of a desiccant wheel. Applied Energy, 104, 268-275.

[29] Angrisani G., Capozzoli A., Minichiello F., Roselli C., Sasso M. (2011), Desiccant wheel regenerated by thermal energy from a microcogenerator: Experimental assessment of the performances. Applied Energy, 88, 1354-1365.

[30] Fathieh F., Nasr M., Sadeh S., Besant R., Evitts R., Müller J., Simonson C. (2016), Determination of air-to-air energy wheels latent effectiveness using humidity step test data. International Journal of Heat and Mass Transfer, 103, 501-515. 
[31] Ali M., Vukovic V., Sahir M., Basciotti D. (2013), Development and validation of a desiccant wheel model calibrated under transient operating conditions. Applied Thermal Engineering, 61, 469-480.

[32] Goodarzia G., Thirukonda N., Heidari S., Akbarzadeh A., Date A. (2017), Performance evaluation of solid desiccant wheel regenerated by waste heat or renewable energy. Energy Procedia, 110, 434-439.

[33] Yamaguchi S., Saito K. (2013), Numerical and experimental performance analysis of rotary desiccant wheels. International Journal of Heat and Mass Transfer, 60, 51-60.
[34] El-Maghlany W., ElHefni A., ElHelw M., Attia A. (2017), Novel air conditioning system configuration combining sensible and desiccant enthalpy wheels. Applied Thermal Engineering, 127, 1-15.

[35] Dehabadi L., Fathieh F., Wilson L., Evitts R., Simonson C. (2017), Study of dehumidification and regeneration in a starch coated energy wheel. American Chemical Society, ACS Sustainable Chem. Eng., 5, 221-223. 